\title{
ANOMALI REFORMASI PENYELENGGARAAN PEMBELAJARAN DI INDONESIA
}

\author{
M. Yusuf T. \\ Fakultas Tarbiyah dan Keguruan UIN Alauddin Makassar \\ Kampus II: Jalan Sultan Alauddin Nomor 36 Samata-Gowa \\ Email: yusta72@gmail.com
}

\begin{abstract}
Abstrak:
Reformasi adalah perubahan berlapis yang berujung pada penciptaan desain baru atas suatu tatanan. Tatanan pendidikan adalah tatanan sangat vital berbangsa yang belum mencapai reformasi utuh bahkan mengalami anomali penyelenggaraan jika memperhatikan orientasi pendidikan nasional setelah UUSPN disahkan. Jika disimak, regulasi pendidikan nasional tersebut telah mengubah paradigma pembelajaran nasional dari paradigma pembentukan perilaku kepada paradigma konstruktifistik. Terjemahan cara baru tersebut ke dalam praktek penyelenggaraan pembelajaran tidaklah mudah, membutuhkan transformasi konseptual yang secara komprehensif bermuara pada sektor mikro pendidikan, yaitu kelas. Argumennya sederhana, kualitas pembelajaran di kelas mengindikasikan kualitas sistem pendidikan secara menyeluruh.
\end{abstract}

\begin{abstract}
:
Reform is layered changes that led to the creation of new designs for an order. Educational settings are vital nation order that has not yet reached full reform implementation even if the notice had anomalous orientation after UUSPN endorsed national education. If you listened to, the national educational regulations have changed the paradigm of national learning paradigm to paradigm constructivism forming behavior. Translation is a new way of organizing learning into practice is not easy, requiring a comprehensive conceptual transformation boils down to the micro sector of education, namely the class. The argument is simple, the quality of learning in the classroom indicate the quality of the education system as a whole.
\end{abstract}

\section{Kata Kunci:}

Reformasi, pendidikan nasional, pembelajaran.

TEMA ini dipilih karena pasca-1998 seringkali didapati generalisasi berlebihan terhadap konsep, gagasan, atau sistem yang dikaitkan dengan gerakan reformasi di Indonesia sejak tahun 1998. Padahal, menurut Banathy, reformasi adalah perubahan lapisan. Lapisan pertama yakni lapisan yang bergerak dari usaha biasa ke doing more of the same but doing it better. Proses awal ini biasanya berhubungan dengan peningkatan efisiensi. Pada gelombang kedua merupakan usaha peningkatan efektivitas dengan mengatur kembali komponen sistem yang ada dan mendistribusikan tanggung jawab pada tiap-tiap komponen. Tahapan ketiga adalah transformasi yang merupakan proses pengkajian komprehensif atas sistem dan penciptaan desain baru. ${ }^{1}$

Berdasarkan tiga tahapan Banathy di atas, tulisan ini mengkritisi perkembangan reformasi bidang pendidikan dengan menghubungkan ranah makro pendidikan nasional hingga ranah mikro yang merupakan terjemahan praksis kebijakan pendidikan 
nasional. Kata "anomali" menunjukkan pandangan minor penulis terhadap reformasi pendidikan nasional yang ditengarai diperlakukan "setengah hati" dan hingga kini belum menunjukkan perubahan substantif.

Dalam pembahasan selanjutnya akan dikemukakan: 1) Rumusan Pendidikan Nasional pasca-reformasi, 2) Arah baru pendidikan, dan 3) Anomali reformasi Pendidikan Nasional.

\section{PEMBAHASAN}

\section{Rumusan Pendidikan Nasional Pasca Reformasi}

Dalam pembukaan UUD RI 1945 disebutkan bahwa tujuan berbangsa adalah mencerdaskan kehidupan bangsa. Kehidupan bangsa yang cerdas ditandai dengan kemampuannya untuk survive di tengah persaingan bangsa-bangsa. Implementasinya dapat dilihat dalam pasal 1 ayat 1 UU RI No. 20 tahun 2003 tentang Sistem Pendidikan Nasional (UUSPN) yang menyebutkan Pendidikan adalah usaha sadar dan terencana untuk mewujudkan suasana belajar dan proses pembelajaran agar peserta didik secara aktif mengembangkan potensi dirinya untuk memiliki kekuatan spiritual keagamaan, pengendalian diri, kepribadian, kecerdasan, akhlak mulia, serta keterampilan yang diperlukan dirinya, masyarakat, bangsa, dan negara.

Rumusan pendidikan tersebut merupakan reformasi konseptual pendidikan nasional. Jika rumusan tersebut dibandingkan dengan rumusan pendidikan dalam UU RI No. 2 tahun 1989 maka terasa perubahannya terletak pada orientasi pengembangannya. UU No. 2 tahun $1989^{2}$ menyebutkan bahwa pembangunan nasional di bidang pendidikan adalah upaya mencerdaskan kehidupan bangsa dan meningkatkan kualitas manusia Indonesia dalam mewujudkan masyarakat yang maju, adil, dan makmur, serta memungkinkan para warganya mengembangkan diri, baik berkenaan dengan aspek jasmaniah maupun rohaniah berdasarkan Pancasila dan UUD RI 1945. Perbandingannya juga kontras jika dibandingkan dengan tujuan Pendidikan Nasional yang dirumuskan dalam GBHN 1993 yang menyebutkan: "Pendidikan Nasional bertujuan untuk meningkatkan kualitas manusia Indonesia, yaitu manusia yang beriman dan bertakwa kepada Tuhan Yang Maha Esa, berbudi pekerti luhur, berkepribadian, mandiri, maju, tangguh, cerdas, kreatif, terampil, berdisiplin, beretos kerja, profesional, bertanggung jawab, dan produktif, serta sehat jasmani dan rohani.

Orientasi "pengembangan potensi diri" seperti dianut UUSPN menekankan konsep diri (self-concepts) yang tidak terumuskan secara jelas dalam rumusan pendidikan sebelumnya. Penekanan itu penting sebagai penegasan paradigmatik bahwa orientasi pengembangan pembelajaran adalah diri siswa. Diri siswa menjadi sentrum pembelajaran sebagai anti-thesis guru sentris yang secara tradisional "menggagalkan" konsep "siswa aktif" yang telah dikenal sebagai metode belajar di Indonesia sejak awal 80-an.

Secara sederhana, Pietrofesa menulis, "The self-concept includes feeling about selfboth physical self and psychological self in relation to the environment". ${ }^{3}$ Jika demikian, 
konsep diri tidak hanya batang fisik dan psikis, tetapi juga diri dalam kaitannya dengan lingkungan. Lebih lanjut, Pietrofesa menguraikan bahwa self-concept dapat dikonstruksi ke dalam tiga dimensi; pertama, dimensi diri seperti dilihat oleh dirinya sendiri, kedua, dimensi diri seperti dilihat oleh orang lain, ketiga, dimensi diri yang ideal. ${ }^{4}$ Dengan demikian, individu tidak saja personal, tetapi juga sekaligus impersonal. Dalam tataran aksiologis pemahaman atas diri dapat dipahami melalui analisis reflektif atas kerangka referensial dan pengalaman individu yang merupakan sumber utama pengetahuan personal.

Penjelasan di atas menguatkan pendapat penulis bahwa rumusan pendidikan nasional setelah reformasi telah menganut paradigma pendidikan humanistik dan konstruktivistik terlihat jelas mempengaruhi cara pandang UUSPN mereformasi makna pendidikan nasional. Tujuan pengembangan potensi diri agar memiliki spiritual keagamaan, pengendalian diri, kepribadian, kecerdasan, akhlak mulia, serta keterampilan yang diperlukan dirinya, masyarakat, bangsa dan negara jelas menunjukkan arah baru pendidikan nasional yang menekankan kemanusiaan yang paripurna.

\section{Arah Baru Pendidikan}

Pendidikan mengalami kontekstualisasi seiring perkembangan masyarakat manusia. Perkembangan mutakhir memunculkan istilah pendidikan alternatif. Pendidikan alternatif sebetulnya berhubungan dengan paradigma pendidikan yang berbeda dengan status quo pendidikan. Paradigma itu sendiri disebut alternatif karena dirasakan oleh dominant society adanya ketidaksesuaian paradigmatik dengan kebutuhan kekinian.

Pasca Perang Dunia II, paradigma pendidikan bergeser lebih condong ke paradigma humanistik. Paradigma pendidikan humanistik seperti dijelaskan Matson, "... is not just study of "human being"; it is a commitment to human becoming". 5 Paradigma ini mengarahkan pendidikan atau lebih spesifik sekolah dikembangkan sebagai pusat pembudayaan dan pengenalan kemanusiaan secara global. Jacques Delors menulis:

While basic education, whatever its duration, should aim to meet the common needs of the population as a whole, secondary education should be the time when the most varied talents are revealed and flourish. Common core elements (language, science, general knowledge) should be enriched and brought up to date, so as to reflect the increasing globalization of phenomena, the need for intercultural understanding and the use of science to foster sustainable human development. ${ }^{6}$

Menjawab kebutuhan global kemanusiaan tersebut, sekolah kini tidak saja sebagai the major level to create a fair and productivity society, tetapi lebih luas berfungsi melayani dan mereproduksi hubungan dalam dunia sosial, ekonomi, dan politik. Perspektif ini melihat sekolah sebagai dominate society yang merupakan silent factor yang meletakkan dan menjaga prinsip-prinsip hidup serta melepaskan ketergantungan individu di dalam kehidupan sosialnya. ${ }^{7}$ Disebut demikian karena sekolah didesain untuk mentransmisi nilai-nilai bermasyarakat yang manifest di dalam kurikulum. Tentu nilai-nilai yang dimaksud adalah nilai-nilai kultural, intelektual, dan 
aesthetic norms dan norma-norma standar. Ethos sekolah ini yang dikenal dengan the hidden curriculum. ${ }^{8}$

\section{Anomali Reformasi Pendidikan Nasional}

Secara makro, bila prioritas reformasi diletakkan pada pendidikan nasional yang memusat, maka tujuan pendidikan pada lapis ini adalah membudayakan atau mengindoktrinasi peserta didik. Konsekuensinya pada lapis pengalaman belajar ditujukan pada keseragaman respon peserta didik terhadap pelajaran. Tetapi bila prioritasnya diletakkan pada lapis pengelolaan, maka tujuannya adalah meningkatkan pengelolaan kegiatan operasional pendidikan. Konsekuensinya pada lapis kelembagaan atau pemerintahan adalah membudayakan dan mendidik peserta didik, serta pada lapis pengalaman belajar ditujukan pada respons peserta didik terhadap pembelajaran. Sedangkan bilamana prioritas diletakkan pada lapis pengalaman belajar, maka tujuan pada lapis ini adalah "menguasai tugas belajar dan mampu mengatasi persoalan belajar". Konsekuensinya pada lapis kelembagaan atau pemerintahan adalah ditujukan pada jaminan ketersediaan sumber guna dalam menunjang pengalaman belajar. ${ }^{9}$

Reformasi Pendidikan Nasional dikembangkan dengan sistem terbuka sebagai bagian integral sistem persekolahan, maka pada hakekatnya prioritas reformasi itu berada pada lapis pengelolaan. Arah reformasi secara konseptual adalah memberikan prioritas pada lapis sistem pembelajaran atau lapis pengalaman belajar. ${ }^{10}$ Secara makro tuntutan reformasi itu dijawab dengan mengganti UU RI No.2 tahun 1989 dengan segala peraturan pelaksanaannya dengan UU RI No. 20 tahun 2003 tentang Sistem Pendidikan Nasional. Pada titik ini kita dapat melihat perbedaan mencolok terutama pada rumusan pendidikan.

Memperhatikan perbedaannya, jelas Sistem Pendidikan Nasional sekarang ini lebih cenderung ke paradigma humanistik dan konstruktivistik. Kata "mengembangkan potensi diri" menjelaskan suatu orientasi baru pengembangan Pendidikan Nasional untuk tujuan-tujuan "memiliki kekuatan spiritual keagamaan, pengendalian diri, kepribadian, kecerdasan, akhlak mulia, serta keterampilan yang diperlukan dirinya, masyarakat, bangsa, dan negara". Rumusan tersebut jika diamati maka sekolah sebagai implementasi mikro rumusan itu semestinya akan menciptakan manusia Indonesia yang berperadaban (madani) unggul.

Persoalannya, apakah orientasi pengembangan organisasi belajar sudah diarahkan mencapai ideal seperti amanat UUSPN itu? Penulis berpandangan minor dengan mengatakan "setengah hati". Ada beberapa indikator penting untuk diajukan: 1) apakah negara telah mengimplementasikan satu sistem pendidikan nasional? 2) apakah pemerintah memiliki peta kebutuhan pendidikan untuk menerjemahkan operasional amanat UU hingga ke tingkat sekolah? 3) apakah sistem rekruitmen guru telah mengalami perubahan yang lebih baik? dan 4) apakah sistem evaluasi belajar memberi efek perbaikan mutu pembelajaran?. 
Pertanyaan-pertanyaan tersebut penting diutarakan untuk menguji seberapa jauh paradigma pendidikan itu telah bergeser ke paradigma humanistik dan konstruktivistik. Pertanyaan pertama mengenai satu sistem pendidikan nasional jelas disoriented. Kecenderungannya sistem pendidikan terpola ke dalam beberapa sistem pendidikan. Polarisasi itu muncul karena gagasan tentang global education dipahami secara intrumental dan abai terhadap substansinya. Akibatnya, sekolah tidak jarang melahirkan siswa yang asocial karena belajar adalah asimilasi intrumental terhadap kebudayaan baru. Lebih celaka karena banyak sekolah yang tidak lagi menghormati identitas kebangsaan karena alasan globalisasi kebablasan. Sekolah disulap menjadi Berstandar Internasional yang banyak kalangan mengasosiasikannya dengan Bertarif Internasional.

Kebijakan pendidikan kesannya tidak terencana baik. Program peningkatan kompetensi guru misalnya tidak sepenuhnya menyampaikan guru pada profesionalitas yang diharapkan. Tambahan insentif yang diharapkan ternyata tidak serta merta mendorong guru untuk memperbaiki performance mengajarnya. Ditambah lagi instrumen yang menjadi acuan menilai untuk sertifikasi guru sedemikian rupa tidak mendorong guru untuk jujur terhadap dirinya. Instrumen-instrumen itu cenderung memerangkap guru dalam kompetisi untuk "lulus segera" karena sistemnya yang tidak fair. Banyak guru yang gagal dan harus menerima kenyataan lulus setelah pensiun karena buruknya administrasi kepegawaian.

Reformasi di bidang "keguruan" nasional kita jelas tidak mendukung pencapaian tujuan pendidikan nasional dan disayangkan karena sistem rekruitmen masih berada pada level just doing as the same thing. Masih seperti dulu yang tidak mengenal kualifikasi selain kualifikasi formal akademik, ijazah, dan akta pendidikan. Idealnya rekruitmen guru diprogram dengan mempersiapkan sumber daya yang cakap dan kompeten untuk mengajar. Kecakapan dan kompetensi seyogyanya telah dibangun sejak dini atau paling tidak saat masuk Fakultas Pendidikan dan Keguruan di Universitas dengan kualifikasi dan insentif khusus karena akan melahirkan lulusan yang vital strategik bagi pembangunan bangsa dalam jangka panjang. Ironis, karena dalam praktek yang bukan lulusan keguruan pun bisa "lulus jadi guru" hanya dengan ikut program (baca: kursus) akta 4.

Kebijakan keguruan di atas tentu menyesakkan oleh karena guru sebagai pendidik dan pengajar memegang peranan vital dan luas dalam masyarakat. Winarno Surakhmad menggambarkan peran itu dengan menulis:

Untuk menjadi pendidik sebagai sektor yang efektif maka guru adalah faktor yang mutlak.

Bukan saja jumlahnya harus mencukupi tetapi juga mutunya harus baik, sebab jumlah

dan mutu guru adalah unsur yang secara langsung ikut menentukan kekuatan seluruh sektor pendidikan. ${ }^{11}$

Sistem evaluasi pendidikan juga tidak kalah melahirkan anomali reformasi yang besar. Ujian nasional hingga sekarang belum menunjukkan signifikansi pengaruh terhadap perbaikan mutu belajar. Efeknya malah memalingkan siswa dari kepercayaan terhadap sekolah formal. Peserta didik berbondong ikut bimbingan 
belajar yang diselenggarakan oleh lembaga pendidikan informal seperti kursus dan privat. Motivasinya jelas adalah kecemasan menyambut ujian akhir atau ujian nasional.

Kecemasan itu beralasan karena sistem ujian nasional kita masih difungsikan sebagai penentu kelulusan siswa. Meskipun terdapat perubahan di sistem ujian nasional tahun 2011, tetap saja merupakan faktor utama penentuan kelulusan. Jika memperhatikan angka-angka ketidaklulusan dari tahun ke tahun menunjukkan grafik yang tidak berubah. Artinya, substansi evaluasinya belum bisa diandalkan untuk memperbaiki sistem pembelajaran di kelas. Di Jawa Tengah misalnya, pada tahun 2005/2006, siswa SMA yang tidak lulus mencapai 63 persen (IPA), 50 persen (IPS) dan 31 persen untuk bahasa. Tahun 2006/2007, siswa SMA yang tidak lulus mencapai 50 persen (IPA), 55 persen (IPS) dan 18,5 persen (Bahasa). ${ }^{12}$

Fenomena ini menambah biaya belajar di Indonesia karena satu masa bimbingan biasanya dipungut biaya yang cukup mahal. Sekolah formal dengan demikian terancam ditinggalkan. Satu-satunya yang tersisa adalah karena sekolah formal menerbitkan ijazah yang sah digunakan, sementara lembaga-lembaga kursus itu tidak memenuhinya.

\section{SIMPULAN}

1. Rumusan Pendidikan Nasional telah mengalami reformasi dengan rumusan yang sangat strategis bagi keberlangsungan masyarakat bangsa Indonesia ke depan.

2. Orientasi pendidikan sejak masa Reformasi lebih menjelaskan bentuknya yang humanistik dan konstruktifistik, dua paradigma yang memungkinkan pembelajaran untuk semakin berbudaya dan berdaya di dalam kehidupannya.

3. Rumusan Pendidikan Nasional belum diterjemahkan secara tepat dan belum menyentuh substansi gagasannya. Penyelenggaraan pendidikan yang terbuka bukannya mendorong peserta didik untuk lebih memahami lingkungannya, malah memalingkannya untuk menjadi manusia asing di dalam komunitasnya. Pendidikan tidak mendorong peserta didik untuk menjiwai ke-Indonesiaan, tapi malah dalam banyak kasus mencabik rasa kebangsaannya dan mengalihkannya ke primordialitas kelompok.

4. Implementasi pendidikan baik pada level makro seperti kesamaan dan kemudahan akses belajar, di level meso seperti sistem rekruitmen tenaga pendidik maupun level mikro misalnya praktek pembelajaran belum mendukung cita-cita Pendidikan Nasional. Di ketiga level itu kita masih menyaksikan anomali-anomali yang anti-thesis terhadap paradigma pendidikan yang dianut Sistem Pendidikan Nasional.

\section{CATATAN AKHIR:}

1. Bela H. Banathy, System Design of Education: A Journey to Create the Future, Englewood Cliffs, NJ., 1991, hal. 7-8.

2. Undang-Undang RI No. 2 tahun 1989. 
3. John J. Pietrofesa, Counseling: Theory, Research, and Practice, Chicago: Rand Mc Nelly Publishing Comp., 1978, h. 85.

4. Ibid, h. 86-87.

5. Floyd W. Matson, "Humanistic Theori: The Third Revolution in Psychologi", dalam P. Zimbardo and C. Maslach, Psychologi for Our Times, Glenview: Foresman and Co., 1973, h. 19.

6. Jacques Delors et. Al., learning the Treasure Within, Report to UNESCO of The International Commission on Education for Twenty-First Century, Paris, UNESCO, 1998, hal. 126.

7. Martin Carnoy and Henry M. Levin, "Educational Reform: Its Meaning?", dalam The Limits of Educational Reform, David McKay Company, Inc, New York., hal. 24.

8. Harold Entwistle, Class, Culture and Education, London, University of Cambridge, 1979, hal. 51.

9. Yusufhadi Miarso, Menyemai Benih Pendidikan, diterbitkan atas kerjasama PUSTEKKOM DIKNAS, 2009, hal. 643.

10. Ibid.

11. Winarno Surakhmat, Guru dan Pendidikannya, Jakarta, Direktorat Pendidikan Guru dan Tenaga Teknis DEPDIKBUD, 1969, hal. 1.

12. Global Post, Edisi Sabtu 7 Maret 2009.

\section{DAFTAR PUSTAKA:}

Banathy, Bela H., System Design of Education: A Journey to Create the Future, Englewood Cliffs, NJ., 1991.

Carnoy, Martin and Henry M.Levin, "Educational Reform: Its Meaning?", dalam The Limits of Educational Reform, David McKay Company, Inc, New York.

Delors, Jacques et. Al., learning the Treasure Within, Report to UNESCO of The International Commission on Education for Twenty-First Century, Paris, UNESCO, 1998.

Entwistle, Harold., Class, Culture and Education, London, University of Cambridge, 1979.

Garis-gari Besar Haluan Negara (GBHN) tahun 1993.

Global Post, Edisi Sabtu 7 Maret 2009.

Matson, Floyd W., "Humanistic Theori: The Third Revolution in Psychologi", dalam P. Zimbardo and C. Maslach, Psychologi for Our Times, Glenview: Foresman and Co., 1973.

Miarso, Yusufhadi., Menyemai Benih Pendidikan, diterbitkan atas kerjasama PUSTEKKOM DIKNAS, 2009.

Pietrofesa, John J., Counseling: Theory, Research, and Practice, Chicago: Rand Mc Nelly Publishing Comp., 1978.

Surakhmat, Winarno., Guru dan Pendidikannya, Jakarta, Direktorat Pendidikan Guru dan Tenaga Teknis DEPDIKBUD, 1969.

Undang-Undang RI No. 2 tahun 1989.

Undang-Undang RI No. 20 tahun 2003. 